\section{A CASE OF SYRINGOMYELIA.}

By FRED. TRESILIAN, M.D., M.R.C.P.EDIN., Enfield.

MANY cases that are at first regarded as instances of progressive muscular atrophy are found on later examination to be cases of syringomyelia. This occurred in the case I wish to record; some years ago it was lectured on and exhibited at examinations as a case of progressive muscular atrophy. The exceptional features in this case are, first, the condition of the left shoulder-joint; secondly, the onset of symptoms much later in life than usually occurs; and, thirdly, a more rapid development of the disease.

W. P., aged 45, was first seen in October, 1898 . He first noticed wasting in the thenar muscles of the left hand about six or seven years ago, without any previous loss of power. Within the last twelve months he has observed a similar wasting in the right thenar muscles. His left shoulder has gradually become swollen to the size it is now within the last four or
five months, and the arm has swelled within the last few days. On examination there was found an enormous swelling around the left shoulderjoint, evidently containing fluid. It was not confined to the joint, but was evidently outside the synovial membrane, as it extended downwards to the insertion of the deltoid and into the axilla, backwards to the supraspinous fossa, and upwards to the clavicle and the upper part of the thorax. There was no pain. The whole of the arm was oedematous down
to the knuckles: He could move the arm freely, and had worked with it to the knuckles: He could move the arm freely, and had worked with it
up to the present. On moving the arm, which was abnormally mobile in all directions, there was distinct grating at the shoulder-joint, with clicking, as from the rubbing of bare or broken bone. There was nothing similar in either the elbow-joints or wrist-joints. Both hands were in a condition of main en griffe, the left being most so, with wasting of the interossei and thenar and hsp pthenar eminences. Sensibility to touch was normal everywhere. Sensibility to pain was lost over the left upper extremity, the shoulder, the side of the neck, and the left side of the thorax. Thermal sensibility was lost over exactly the same region. On the right side the sensations appeared to be normal, save around the no weakness or rigidity of the legs, and no inco-ordination. There was no weakness or rigidity or the legs, and no inco-ordination. The knee. ankle clonus. Nystagmus was pri se had distinct but not prolonged showed the characteristic changes or myopia, and the fundi were otherwise normal. The laryngoscopo shower weak abduction of the left vocal cord, it was not immobile, but was much less brisk in its movement than its fellow.

I made him rest from work, and in a few days the cedema of the arm went down considerably, and then I could see that the small muscles of the left hand were much more atrophied than those of the right. I aspirated the shoulder-joint, and got away about 6 ounces of gelatinous blood-stained fluid, which was only a small portion of what the joint contained, but though I moved the needle about in various directions no more would flow away. I think it must have been loculated by adhesions. The operation gave him no pain whatever, and he did not feel the introduction of the needle. He returned to his work, which he refused to give up, as he felt able to do it satisfactorily, and I have only seen him once since, when he was in exactly the same condition.

This man had noticed no symptoms in childhood. He never had any condition of whitlows, or ulcers, or chilblains, though he remarked since the onset of the disease, that if he burnt or cut his left hand it did not give him pain. The left shoulder-joint exhibited a condition exactly similar to that of advanced "Charcot's disease" as seen in tabes. There was evidently disorganisation of the joint, with destruction of the head of the humerus. This did not interfere with the power of the arm.

It will be interesting to watch if his laryngeal abductor paresis becomes absolute, and if any other signs of implication of the medulla are exhibited in the progress of the disease.

\section{THE TREATMENT OF MALARIAL FEVERS BY THE INUNCTION OF CREOSOTE.}

By Major A. O. FITZGERALD, R A.M.C., L.R.C.P.I., Medical Officer in Charge of the Station Hospital, Belgaum.

Mr attention was first directed to the utility of creosote inunction by a note in the British MEDICAL JoURnaL of January 4th, 1896, by Surgeon-Lieutenant Leonard Rogers, M.B., F.R.C.S. I have not strictly followed the method or dosage mentioned in his publication, but have varied them as follows : Pure beechwood creosote, 15 to 20 minims for a child of I year, or 30 to 60 minims for an adult, was mixed with an equal quantity, or more, of olive oil, and rubbed, for from five to ten minutes, over the chest, abdomen, axillæ, and sides. The oil was only employed to counteract the tingling and burning occasionally produced by the creosote.

The accompanying table contains cases of malarial fevers alone, as I wish to draw attention to the specific action the treatment appears to have in them. Their number, I am aware, is too limited to prove anything absolutely; but as equally good results were obtained in many more cases during the past year, notes of which it was impossible to take owing to pressure of work, I think it permissible to forward this report now.

A glance at the table will show that the results are remarkably uniform. In Class I, in the majority of cases, the usual remedies had been tried, and were continued afterwards, so the creosote may be looked on as merely an adjuvant. In Class II the Cases XIII and XVI to XXIII were treated with creosote as soon as they came into hospital, and nothing else was given, so that a secondary place cannot be given to it in these while, in Class III the results were so striking in cutting short the disease and preventing recurrences, that $I$ give the first four in detail as typical examples of the class of case in which the treatment may be found most useful. Before doing so I may refer briefly to a few of the cases in the other classes.

\section{Crass I.}

CASE III.-The usual treatment had utterly failed. The temperature remained between $103^{\circ}$ and $105^{\circ} \mathrm{F}$. The patient was getting worse. At first mxv ter die were ordered first, but as the effects were not marked the dose was increased to 3ss. ter die. The husband was too energetic, and rubbed it in nine times on June 7 th, 1896, but no unpleasant symptoms followed, and 3ss. ter die was continued until the temperature fell to normal. The tongue began to clean, and sleep was obtained after the first inunction, and it was very remarkable how the appetite returned, and the patient asked for food on the second day of treatment.

CASE IV.-This patient had just come down country saturated with malaria Helived in quarters by himself, and when seen first was semi-delirious; all his servants were sick, and he had no one to look after him or administer medicine. Under these conditions the value of the treatment is well exemplified : 3 ss was rubbed in twice on evening of June roth, 1896. He fell asleep shortly after, and continued asleep well into the next day without any other treatment. On the evening of irth he felt better than he had tion for a week. and had no recurrence during that reme.ned in the stato continue taking quinine, arsenic, iron, and strychnine owing to his to continue taking

\section{Crass II.}

CASE XV.-An old soldier, cachectic and emaciated, had been subject to frequent bad attacks of ague, which sometimes assumed a continued his cachectic condition. He is now fat, strong, and with a good colour his cachectic condition. He

Class III.

The dosage in this class was out of proportion larger than in the others, and to this may be due the fact that the results are more striking, the conclusion being, I think, that the dose for adults might be greatly increased with advantage. The first four I will now give in detail.

CASE I. -A. D. F., aged 1 , was suffering from continued malarial fever. and had had no sleep for at least twenty-tour hours. He had been previously treat ex with ordinary remedies. On June 6th, 1896, vomiting had of quinine were rejected at once. At 9 P.M. the temperature was $103^{\circ} \mathrm{F}$. of quinine were rejected at once. At 9 P.M. the temperature was $103^{\circ} \mathrm{F}$., tity of olive oil was rubbed in over the chest and sides. The effect was practically instantaneous, the spasms became gradually less, the patient practically instantaneous, the spasms became gradually less, the patien temperature had fallen to ed ind the easy sleep. In half an hour the effect continued throughout the night, and the vomiting having ceased he was able to take his food. On June 7 th, at 7.30 A.M., the temperature was ror $^{\circ} \mathbf{F}$., but none of the graver symptoms had returned. The same quantity of creosote and oil was rubbed in, after which the temperature gradually fell. The patient was quite comfortable all day, sleeping at intervals. and finally sank into a deep sleep at 7 P.M. ; he scarcely stirred until the
following morning, when the temperature was normal. There was no recurrence, and no further treatment was required.

CASE VI.-E. F. G., aged 4 years Ir months, was suffering from malariaI fever, with bilious vomiting and purging, which prevented any medicine or food being retained. The temperature rose gradually for three days, until on the morning of June 24 th, 1896 , it was ro4 ${ }^{\circ} \mathrm{F}$. Creosote mxv with an equal quantity of olive oil was rubbed in at $7.3^{\circ}$ A.M. . after which she slept an hour and a-half. The temperature continued to rise until a 6 P.M. it was ro $5^{\circ} \mathrm{F}$. : $\mathrm{mxxv}$ of creosote with oil were then rubbed in. This relieved all the symptoms, and the patient slept well the whole night. The temperature gradually fell to normal on June 27 th without the July ist she was in her usual health. There was no recurrence.

CASE IX.-E. F., aged 4, was suffering from malarial fever of an intercase 1X. - . . ., aged 4, was surfering from malarial fever of an intermittent tertian type, and was taking liquor arsenicalis and quinine with diaphoretics and potassium bromide. At 2 P.M. On July 31 st, 1896, she was very restless and becoming delirious. She was apparently suffering much pain. The temperature, taken in the groin, was $103.4^{\circ} \mathrm{F}$., but was proonce over the chest, abdomen, and sides, and as I rubbed the child gradu- 
Chass I.-Adults treated out of Hospital.

Station-Rangoon.

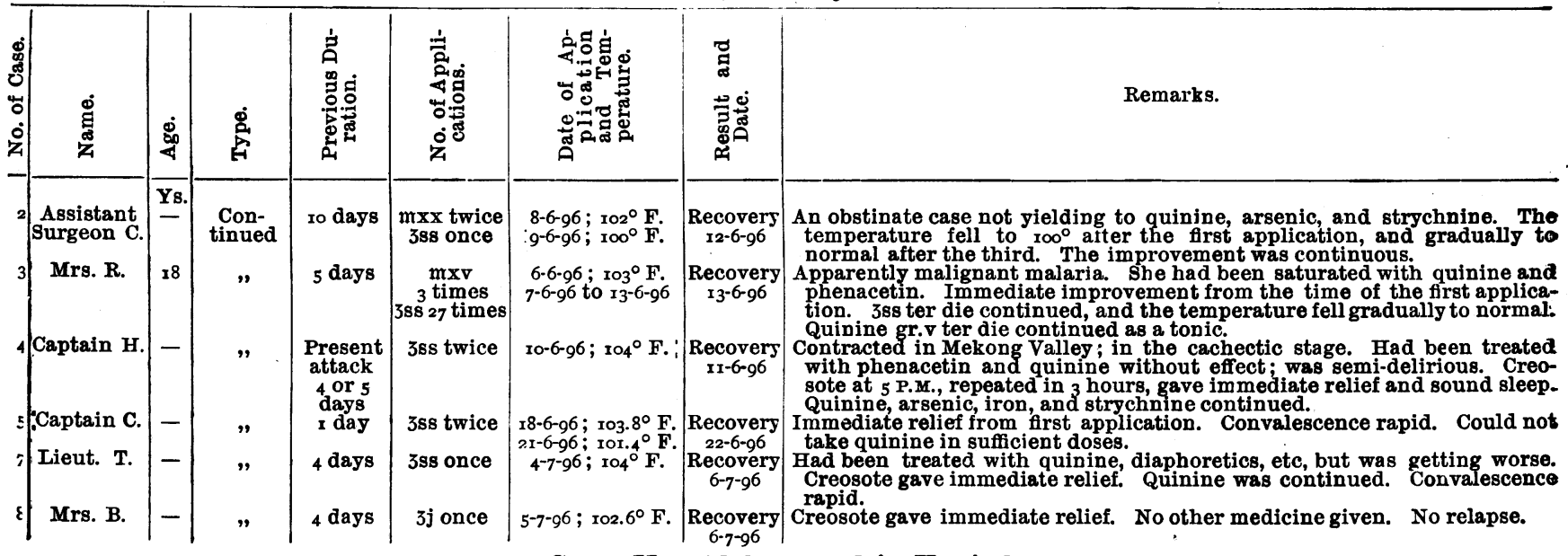

Class II.-Adults treated in Hospital.

Station-Rangoon.

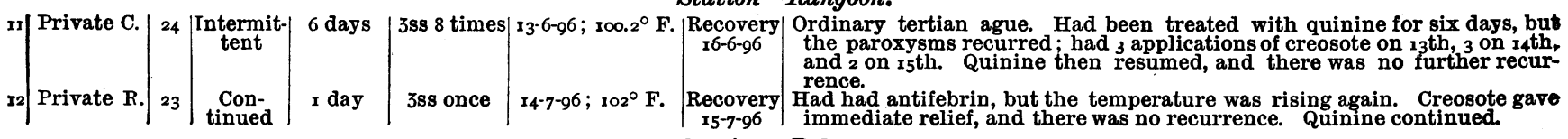
Station-Belgaum.

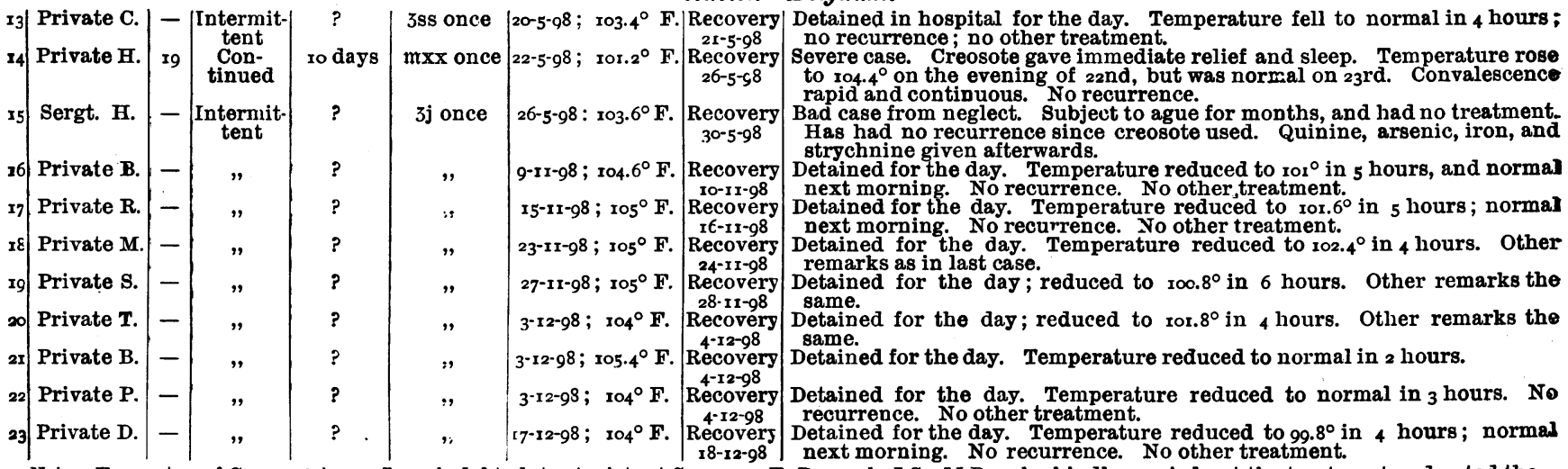
Note.-For notes of Cases 16 to $23, \mathrm{~T}$ am indebted to Assistant-Surgeon E. Peacock, I.S., M.D., who kindly carried out the treatment and noted the effects at different stagi $s$. Relief was immediate in each case, and followed by $1 \frac{1}{2}$ to 2 hours' sleep.

CLASS III.-Children treated out of Hospital.

Station-Rangoon.

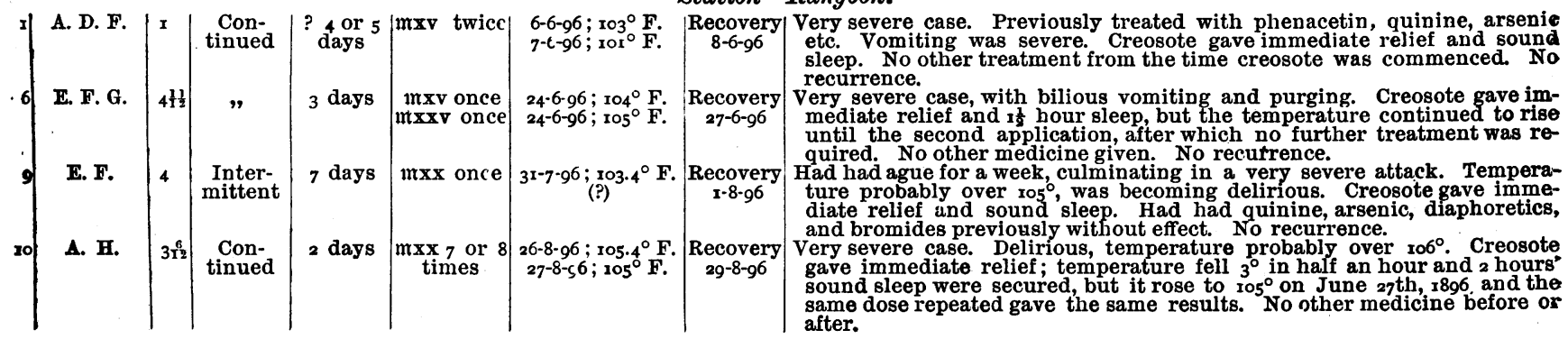

Station-Belgaum.

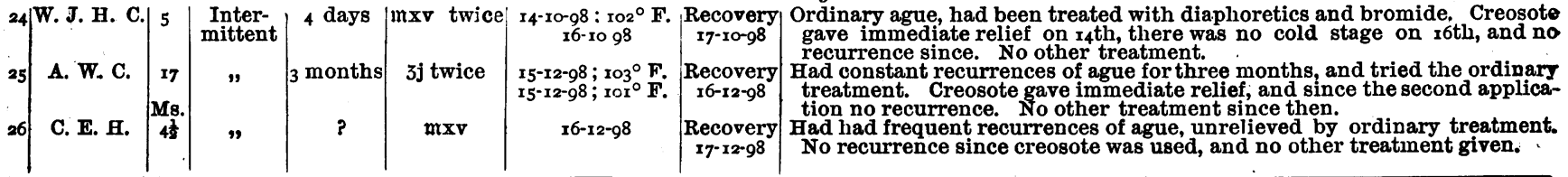
Note.-For notes of Cases 24 to 26 I am indebtəd to Assis ant Surgeon F. J. Caneck, I.M.S., M.D., who kindly carried out the treatment and kept, cases under observation. 
ally ceased to cry and toss about, her expression was one of extreme relief, and before I had finished she was sound asleep. She slept soundly for two hours, and there was no return of the symptoms on waking. In the morning the temperature was normal. She was keptin bed for three fever The arenic and quinine mixture which she had been taking before fever. The arsenic

CASE X.-A. H., aged $3^{\frac{1}{2}}$, was suffering from malarial fever aggravated by neglect and exposure to the sun. Her mother stated that she was subject to ague, and had had fever for two days. She had not been kept in bed, and she would not take any medicine. I was called in at Ir P.M. on August 26th, 1896, and found the child quite delirious. The temperature taken in the groin was ro5.4 $4^{\circ}$ F., but probably nearer 1o ${ }^{\circ}$ in the mouth. I rubbed in mxx of creosote at once, and the effect was almost instantaneous; the delirium ceased rapidly, she became conscious, then was very irritable for a few minutes, and in a few minutes more was quite comfortable and quiet. In half an hour the temperature had fallen 3 degrees. She slept soundly for two hours, and fairly well for the rest of the night. On August 27 th, 1896, at 7 A.M. the temperature was $100^{\circ} \mathrm{F}$., but rose to $105^{\circ}$ at ro A.M., with internal strabismus and commencing convulsions. The inunction of creosote (mxx) repeated gave immediate relief. Some creosote and oil were prescribed in $1 \mathrm{mxx}$ doses, to be rubbed in if the temperature rose again over $103^{\circ}$, but the mother, becoming impatient. rubbed it in five or six times in the course of the next twenty-four hours. This indiscretion, however, was followed by no bad results. The temperature fell to normal on the morning of August 2gth, without any other reament. There was no recurrence.

Though I regret that I have been unable to keep notes of other cases, I do not think it necessary that anything should be added to this record to prove the value of the treatment. My object is simply to bring it to notice, particularly in the interests of the last class of cases, which are frequently found so very difficult to treat by other means. Personally I never now answer a call to a sick child night or day without taking a small bottle of creosote with me. In this way time is saved, which perhaps could never be made up if lost.

It appears to me to be an ideal treatment for malarial fevers in children, as it combines everything that is necessary, even in very severe cases ; it is easily applied; it acts rapidly and continuously, and, as far as my experience goes, with certainty ; and I have never seen any bad effects, even after the excessive use of the drug. I need only allude to the possibilities of treatment of the more malignant forms of malarial fevers by the external or internal administration of this drug.

\section{FIVE CASES OF SO-CALLED BLACKWATER FEVER.}

BY H. M. DOWLER, L.R.C.P.LOND., M.R.C.S.ENG., Gairkatta, Dooars, Bengal.

The following five cases have occurred in this district within the last two years. A typical case is as follows:

A European tea planter, aged 23 , had felt feverish for a few days pre ceding April 8th, r899, on which date he passed about 8 ounces of urine having the appearance of porter, and containing albumen. The skin and conjunctivæ were japundiced. He had pain in the dorso-lumbar region and joints, and felt very weak. There was slight headache, and he had had bilious vomiting for a few hours. He was sweating freely. There were no other abnormal physical signs. A rigor with vomiting came on temperature. Quinine bihydrochlorate gr. iij given hypodermically at once, with liq. hydrarg. perchlor. mx given at ten-minute intervals, soon checked the vomiting. Lithium benzoate was also given, in gr. $v$ doses, two more gr. iij doses of quinine were given hypodermically, and the temperature fell from $99.4^{\circ}$ on the second day to $99^{\circ}$ on the third, after which it had a considerable range from subnormal to normal until the eleventh day, when it reached ${ }^{\circ} 0.2^{\circ}$, but the continued use of quinine then brought the temperature to normal. The smallest quantity of urine passed was 17 ounces on the fourth day, but by the fifth day it had increased to 43 ounces daily, when the lithium benzoate was stopped. The colour of the urine varied from that of porter through various shades of reddish brown. On the fourth day there was no trace of albumen. He sweated freely and slept well thronghout. An occasional soap enema was necessary. His diet consisted of milk diluted with soda-water or limewater in small quantities every few minutes, vermicelli, sago, and tapioca. Aays. Animal food was given as soon as the urine was free from albumen ouinine was given hypodermically from the eleventh to the twenty-first day. The patient was then given Easton's syrup ziij daily, and was advised to leave this malarial place and to take a sea voyage.

Four months ago an educated Bengali had a similar attack, for the symptoms and treatment of which the preceding case will well stand as a type. He made a good recovery. For the first eight days I tested his urine, which varied from I ounce on the second day to an average of $I$ pint during the next six. The first specimen was neutral, the remainder acid; the specific gravity varied from 1020 to 1013, and I failed to detect in it any sugar, bile pigments, or bile salts. It contained about one-fifth of albumen at first, but this was absent on the fourth day. Microscopically no blood corpuscles could be detected, but the urine (more especially the reddish-brown sediment) was full of what appeared to be pale yellow granular casts, which noticeably decreased in amount as the urine became lighter coloured. I regret to say that I had no means for the detection of blood-colouring matter.

I have also treated three other cases in Europeans which were fatal.

In the five cases the highest temperature was $103.7^{\circ}$ and the highest pulse-rate 108; the greatest amount of albumen was one-half. There was sometimes slight diarrhœa during the attack. The prostration was marked in all, and there was a tendency to syncope on attempted movement. In all cases also there was dark grass-green bilious vomiting, with uncontrollable hiccoush in one of them, slight enlargement of the spleen in one case ; there was no enlargement, 'pain or tenderness of either the spleen or liver. Of four Europeans, one was big built and flabby, while three were muscular and stronglooking men. Three had been free from malaria for some time previously, but three bad had a great deal of mental worry preceding the attack. None had taken large doses of quinine.

The hypodermic method is undoubtedly the best method of administering quinine in such cases, and lithium is retained in the stomach much better than the more usually employed diuretics. Liq. hydrarg. perchlor. appears to be the most serviceable drug to allay the vomiting, for which purpose a soap enema is usually a great aid, and a mustard plaster on the epigastrium also gives a very satisfactory result. On account of the syncopal tendency a stimulant mixture is generally needed.

From my own experience and inquiries it seems that this is a very rare complaint amongst natives, who are in the habit of stating that they pass blood in the urine when it is merely of a high colour due to malaria. On the other hand, it has been suggested with strong probability that, owing to the ignorance and carelessness of the large majority of local native practitioners in diagnosing it, the disease is not so rare amongst them as is usually supposed.

Blackwater fever differs from malaria accompanied with bilious vomiting so common in this district in (I) the character of urine; (2) the temperature not running so high, seldom above ror ; (3) the muscular weakness and prostration; and (4) the syncopal tendency. But, in spite of these differences, the two complaints have very similar symptoms, and the idea suggests itself whether the differences do not depend more on degree than character, and whether they may not both be due to very similar, if not the same, causes.

\section{ME M O RAN DA:}

MEDICAL, SURGICAL, OBSTETRICAL, THERAPEUTICAL, PATHOLOGICAL, ETc.

ULCERATION OF COLON IN TYPHOID FEVER.

THE following case I think worthy of note chiefly on account of the length of time that elapsed between the probable date of perforation and that on which death took place, but also for the extensive perforations of the large intestine.

The patient, a bov aged 7 years, was admitted into the Foleshill Infectious Hospital on May 18th, 1898 . The temperature on admission was $99^{\circ}$, and he was thought to be in the second week of typhoid from the history. The temperature next morning was $101.2^{\circ}$ and then rose during the next five days with but three morning remissions to $104^{\circ}$ at 5 P.M. on May 24th. It regained then the ordinary remittent type, not rising above $102^{\circ}$, the diarrhoea at this time having become very troublesome, eight or nine times in the twenty-four hours, was only checked by starch enemata. On May 27th a swelling with a good deal of cutaneous redness was noticed in the umbilical region, reducible on pressure; under poultices the redness disappeared and the swelling decreased in size; in two days however a great increase took place and the tissues became much inflamed; peritoneal abscess, was diagnosed and about 4 ozs. of fœit pus removed by aspiration on May 31 st. The swelling reappeared however in a day or two as large as 